\title{
1 Spatial scales of genetic patchiness in the western rock lobster
}

2 (Panulirus cygnus)

3

4

5

6

7

8

9

10

11

12

13

14

15

16

17
W. J. KENNINGTON ${ }^{\mathrm{A}}$, O. BERRY ${ }^{\mathrm{A}, \mathrm{B}}$, D. M. GROTH ${ }^{\mathrm{C}}$, M. S. JOHNSON ${ }^{\mathrm{A}}$ and R. MELVILLE-SMITH ${ }^{\mathrm{D}}$

${ }^{\mathrm{A}}$ School of Animal Biology, The University of Western Australia, Crawley, WA 6009, Australia

${ }^{\mathrm{B}}$ CSIRO Division of Marine and Atmospheric Research, Underwood Avenue, Floreat, WA 6014, Australia

${ }^{\mathrm{C}}$ Curtin Health Innovation Research Institute, Biomedical Research Institute, Curtin University, GPO Box U1987, Perth, WA 6845, Australia

${ }^{\mathrm{D}}$ Department of Environment and Agriculture, Curtin University, GPO Box U1987, Perth WA 6845, Australia

Key words: western rock lobster, genetic variation, microsatellites, population structure, sweepstakes reproductive success

Running title: Spatial genetic patchiness in the western rock lobster

Corresponding author: Jason Kennington, School of Animal Biology, The University of Western Australia, Crawley WA 6009, Australia.

Tel.: +61864883233

Fax: +61 864881029

E-mail: jason.kennington@uwa.edu.au 


\section{Abstract}

32 In planktonic dispersers, impediments to dispersal, local selection or large variance in the

33 reproductive success among individuals (sweepstakes reproductive success) can create

34 genetic heterogeneity at local scales. While these processes are well recognized, relatively

35 few studies have investigated the spatial scales over which genetic heterogeneity occurs and

36 how it is distributed across species' ranges. We investigate population structure in the

37 western rock lobster (Panulirus cygnus), a commercially exploited species found in shallow

38 and deep water reef habitats along the Western Australia coastline. We screened 631

39 individuals from nine locations across the species' range for genetic variation at 22

40 microsatellite loci. Consistent with expectations of extensive larval mixing during an

41 extended planktonic stage, we found no significant genetic differentiation among the nine

42 locations $\left(F_{\mathrm{ST}}=0.003, G\right.$ ' ' $\left.{ }_{\mathrm{ST}}=0.007\right)$. Despite the lack of large-scale geographic structure, small but significant positive spatial autocorrelation (SA) was detected over distances up to $40 \mathrm{~km}$. Two-dimensional local SA analysis confirmed that fine-scale genetic heterogeneity was common throughout the species' range. An intriguing aspect of these results was that

46 they were based on juvenile and adult lobsters, suggesting restricted movement or spatial 47 cohesion of individuals after settlement. 
The spatial extent of genetic structure is largely dependent on the dispersal capacity of individuals (Bohonak 1999). This is especially apparent in the marine environment, where species with planktotrophic larvae that spend months in the water column tend to maintain low levels of genetic structure across large geographic scales, while those with short planktotrophic larval phases or direct developers usually have much higher levels of subdivision (Waples 1987, Palumbi 1994, Johnson \& Black 2006a, Lee \& Boulding 2009). However, the role of dispersal capacity in structuring marine populations is complex, and can be strongly influenced by other factors. For example, in spiny lobsters, most species are characterized by a lack of genetic differentiation among localities, consistent with their high dispersal capability during an extended planktonic larval stage (e.g., Ovenden et al. 1992, Silberman et al. 1994, Tolley et al. 2005, García-Rodrguez \& Perez-Enriquez 2008, NaroMaciel et al. 2011), but in some species, barriers to dispersal created by topographic or oceanographic features can lead to moderate to high levels of population structure (PerezEnriquez et al. 2001, Gopal et al. 2006, Palero et al. 2008). between populations on different islands compared to different populations on the same island in both a direct developing snail and a planktonic disperser. Such genetic heterogeneity at local scales can occur even when there is little genetic subdivision over large distances (e.g., Hedgecock 1986, Benzie \& Stoddart 1992, Johnson et al. 1993, Ayre \& Hughes 2000). Adaptation to local environments (e.g. low salinity or temperature) can also lead to genetic differentiation at selected and linked neutral loci, despite high levels of gene flow (see Nielsen et al. 2009). The extent of population structure can therefore vary considerably among species and is not always determined by life-history characteristics alone. For 
commercially exploited species, failure to detect underlying population structure is a concern, because it may result in overexploitation and depletion of localized subpopulations, with a corresponding loss of genetic variation (Carvalho \& Hauser 1994, Begg et al. 1999).

The western rock lobster Panulirus cygnus (Decapoda: Palinuridae) is found in shallow and deep water reef habitats along the Western Australia coastline, from Cape Leeuwin $\left(34^{\circ}\right.$ $\left.22^{\prime} \mathrm{S}\right)$ to North West Cape $\left(21^{\circ} 45^{\prime} \mathrm{S}\right)$. It supports one of the most economically important single species fisheries in Australia, with until recently, an annual commercial catch of between 8000 and $14500 t$ (Fletcher et al. 2005). A key assumption underlying the management of $P$. cygnus is that the breeding stock comprises a single, demographically united population. This assumption is based on the extended pelagic larval stage of $P$. cygnus, which is thought to ensure high dispersal throughout the species' range. Larvae hatch in spring and early summer, and spend the next nine to eleven months in the plankton, with mid stages being found up to $1500 \mathrm{~km}$ offshore. The late-stage larvae metamorphose into pueruli and swim inshore to start the juvenile stage of their life-cycle (Phillips et al. 1979). Allozyme studies also suggest $P$. cygnus is a single panmictic population, but with ephemeral genetic patchiness (small-scale genetic heterogeneity among local populations) caused by temporal variation in allele frequencies of recruits (Thompson et al. 1996, Johnson \& Wernham 1999). It therefore represents an extreme model for testing for subtle fine-scale genetic structure over a large geographic range. The aim of this study was to investigate the spatial scale of genetic patchiness in juvenile and adult $P$. cygnus across the main geographic distribution of the species. To achieve a resolution beyond previous genetic studies, we sampled at finer spatial scales, and used 22 microsatellite loci for our study. Microsatellites have proven to be a powerful tool for detecting genetic subdivision within marine species with high larval dispersal capabilities (e.g., Knutsen et al. 2003, Riccioni et al. 2010, White et al. 2010) and 
have revealed spatial genetic structure on finer scales than found with allozymes and mtDNA (e.g., Ruzzante et al. 1996, Jørgensen et al. 2005).

\section{Materials and methods}

\section{Sample collection}

In 2009, tissue samples were collected from juvenile and adult $P$. cygnus (carapace length > $45 \mathrm{~mm}$ ) at nine locations spanning nearly $660 \mathrm{~km}$ along the Western Australian coastline (Fig. 1). A total of 631 individuals were captured using commercial lobster pots set over distances up to $27.4 \mathrm{~km}$ apart within each location. Sample sizes at each location ranged between 19 and 64 individuals. To allow investigation of fine-scale patterns within the Houtman Abrolhos Islands, samples were collected from an additional seven sites (eight sites in total) between four and $82 \mathrm{~km}$ apart (sample sizes ranged between 40 and 68 individuals). The spatial coordinates for each individual were recorded at the time of capture.

\section{DNA extraction and microsatellite genotyping}

DNA was extracted from the middle lobe of the tail fan stored in $100 \%$ ethanol, using a QIAGEN Dneasy Blood and Tissue kit, following the manufacturer's recommendations. After the DNA was extracted, each sample was analysed using a NanoDrop ND-1000 spectrophotometer to determine the concentration and quality of the DNA. All DNA samples were stored at $-20^{\circ} \mathrm{C}$ until genotyping. Genotypes at 22 microsatellite loci (S3, S8, S28, S50, W25, Pcyg1 - 9 and 11-18) were determined for each individual using primers and PCR running conditions described in Groth et al. (2009) and Kennington et al. (2010). PCR products were analyzed on an ABI 3700 sequencer using a GeneScan-500 LIZ internal size standard and scored using GENEMARKER (SoftGenetics, State College, PA, USA) software. 
Microsatellite variation at each location was quantified by calculating allelic richness (a measure of the number of alleles independent of sample size) and Nei's (1987) estimator of gene diversity. The presence of null alleles was tested for each locus using MICROCHECKER (van Oosterhout et al. 2004). Tests for a deficit or excess in heterozygotes at each location were carried out using randomisation tests, and the results were characterized using the $F_{\text {IS }}$ statistic. Significantly positive $F_{\text {IS }}$ values indicate a deficit of heterozygotes relative to random mating, and negative values indicate an excess of heterozygotes. Linkage tested using Friedman's ANOVA. To test for a relationship between genetic and geographical distance, we compared a matrix of $G$ "' 
Spatial genetic structure was also investigated using two Bayesian clustering methods, implemented with the software packages STRUCTURE (Pritchard et al. 2000) and GENELAND (Guillot et al. 2005). Both these programs group individuals into the most likely number of clusters $(K)$ that maximizes the within cluster Hardy-Weinberg and linkage equilibria. However, GENELAND differs from STRUCTURE in that geographical information can be incorporated to produce more accurate inferences of population structure based on the spatial distribution of individuals. Analyses involving STRUCTURE were based on an ancestry model that assumed admixture and correlated allele frequencies. No prior information about the origin of the samples was used. Ten independent runs were performed for each value of $K(1-$ 10), with a burnin of 10000 followed by 100000 MCMC iterations. The most likely number of clusters was assessed by comparing the likelihood of the data for different values of $K$ and using the $\Delta K$ method of Evanno et al. (2005). For the GENELAND analysis, the spatial coordinates (latitude and longitude) of each individual were used to run the spatial model. The uncertainty of coordinates was set at zero. Ten independent runs were performed for autocorrelation are influenced by the size of distance classes (see Peakall et al. 2003), $r$ was 
structure is present, $r$ will decrease with increasing distance class sizes. The distance class where $r$ no longer differs significantly from zero provides an approximation of the extent of detectable positive spatial genetic structure (Peakall et al. 2003). Tests for statistical significance were performed by random permutation and calculating the bootstrap 95\% confidence limits (CL) of $r$, using 1000 replicates in each case. We also performed a twodimensional local spatial autocorrelation analysis using GENALEX. With this analysis, the local autocorrelation $(l r)$ is estimated by comparing an individual with its $n$ nearest neighbours, allowing investigation of local patterns of spatial autocorrelation within the two dimensional landscape (Double et al. 2005). Calculations of $l r$ were made using the nearest five, 10, 20 and 50 individuals. As with the global autocorrelation analysis, statistical significance was determined using permutation tests.

Finally, tests for selection acting on marker loci were carried out using the $F_{\text {ST }}$ outlier approach (Beaumont \& Nichols 1996, Beaumont 2005), implemented with the LOSITAN software package (Antoa et al. 2008). The method evaluates the relationship between $F_{\mathrm{ST}}$ and expected heterozygosity in an island model of migration with neutral markers. This distribution is used to identify loci with excessively high or low $F_{\mathrm{ST}}$ values compared to neutral expectations. These loci are candidates for being subject to directional and balancing selection respectively. Simulations were run using 10000 replications, 99\% confidence intervals and the neutral and forced mean options. For this analysis, individuals were grouped by location and both the stepwise and infinite allele mutation models were performed.

\section{Results}

Thirteen loci (S3, S8, S50, Pcyg02, Pcyg04, Pcyg06, Pcyg07, Pcyg09, Pcyg12, Pcyg13, Pcyg14, Pcyg16 and Pcyg17) were identified as having null alleles in at least one location using MICROCHECKER and excluded from further analyses unless specified otherwise. The 
remaining loci showed high levels of genetic diversity at each location (Table 1). There were no significant differences in allelic richness $\left(\chi^{2}=11.57, P=0.172\right)$, gene diversity $\left(\chi^{2}=6.89\right.$, $P=0.548)$ or $F_{\mathrm{IS}}\left(\chi^{2}=3.11, P=0.927\right)$ among locations. Nor was there genotypic disequilibrium between pairs of loci after adjusting for multiple comparisons or deviations from Hardy-Weinberg Equilibrium (HWE).

There was no significant genetic differentiation among the nine sampling locations $\left(F_{\mathrm{ST}}\right.$ $\left.=0.003, G^{\prime}{ }_{\mathrm{ST}}=0.007, P=0.249\right)$. Most tests of population differentiation between pairs of locations were non-significant (Table 2), and divergences between most locations were comparable to those observed between sampling sites within the Houtman Abrolhos Islands (pairwise $G$ "'sт ranged from -0.015 to 0.020 ), which were separated by much smaller geographical distances. There was no evidence for isolation-by-distance using pairwise $G$ "'sT values calculated between locations (broad-scale) or between sampling sites within the Houtman Abrolhos Islands (local-scale) (Mantel tests, $P=0.170$ and 0.111 respectively). No significant genetic divergences among locations were also found when analyses were performed using all 22 loci $\left(F_{\mathrm{ST}}=0.000, G{ }^{\prime}{ }_{\mathrm{ST}}=0.000, P=0.595\right)$. We also failed to detect isolation-by-distance when analyses were performed using all 22 loci (Mantel tests, $P=0.170$ and 0.453 for broad and local spatial scales respectively).

No genetic subdivision was found using Bayesian clustering analysis. The STRUCTURE analysis revealed decreasing log probability estimates with increasing values of $K$ and there were no large fluctuations in $\Delta K$, suggesting that the probable number of clusters was one. Further, when $K>1$, the proportion of individuals assigned to each cluster was fairly even and most individuals were admixed, consistent with inferred population structure not being real (Pritchard et al. 2010). The analysis involving GENELAND gave a similar result, with posterior distributions of the estimated number of populations indicating a clear mode at $K=$ 1 in nine out of 10 replicates. Similar results were obtained when clustering analysis were 
performed using all 22 loci, with the STRUCTURE analysis revealing only slight increases in $\log$ probability estimates with increasing values of $K$ and no large fluctuations in $\Delta K$, while the GENELAND analysis indicated a clear mode at $K=1$ in all 10 replicates.

In contrast to the Mantel tests, spatial genetic structure was detected with the SA analyses. Significantly positive $r$ values were found within the first four distance classes $(0-$ $10,11-20,21-30$ and $31-40 \mathrm{~km}$ ), after which $r$ decreased and oscillated between being nonsignificantly different from zero and significantly negative (Fig. 2A). This pattern is indicative of fine-scale spatial genetic structure generated by discrete patches of similar multilocus genotypes (Smouse \& Peakall 1999, Diniz-Filho \& Telles 2002). Positive spatial genetic structure at local geographical scales was confirmed when estimates of $r$ were calculated with increasing distance class sizes. Figure 2B shows little change in $r$ between 10 and $100 \mathrm{~km}$, after which $r$ decreased, but remained significant until $150 \mathrm{~km}$. It also appears that positive genetic structure was not confined to one geographical area. Two-dimensional local spatial autocorrelation analysis revealed clusters of positive $l r$ at most sampling locations (Fig. 3). The close proximity of significantly positive and non-significant values suggests that local patches were not genetically uniform. A similar number and distribution of positive $l r$ values were obtained when calculations were based on sampling the nearest five, 10, 20 and 50 individuals, confirming the consistency of the result. Again, similar results to these were found when all 22 loci were used. The only exceptions being that in the SA analysis positive $r$ values were found within the first two distance classes only and none of the remaining distance classes were significantly negative. The outlier analyses failed to detect any loci with higher than expected $F_{\mathrm{ST}}$ values. 
246 The major finding of this study was the significant genetic heterogeneity among local

247 populations in $P$. cygnus, over very short spatial scales, without the presence of large-scale

248 geographic structure. We found extremely low levels of differentiation among locations

249 sampled across the species' range $\left(F_{\mathrm{ST}}=0.003, G{ }^{\prime \prime}{ }_{\mathrm{ST}}=0.007\right)$, consistent with extensive

250 gene flow over large geographic distances. The lack of geographic pattern was emphasized

251 by genetic divergences between locations separated by distances over $650 \mathrm{~km}$ being no larger

252 than the divergences between sites at the Houtman Abrolhos Islands, which are separated by

253 distances less than $85 \mathrm{~km}$. We also found no evidence of isolation-by-distance using pairwise

$254 G$ 'sт estimates and no genetic subdivision using Bayesian clustering analysis. Our results, therefore, add weight to the findings of previous allozyme (Thompson et al. 1996, Johnson \&

Wernham 1999) and microsatellite studies (Kennington et al. 2013), which suggest that $P$. cygnus is a single, panmictic population.

Fine-scale population structure in P. cygnus was most clearly evident with spatial autocorrelation analysis. Significant genetic structure was observed when lobsters were sampled over distances up to $40 \mathrm{~km}$, with detectable positive spatial genetic structure extending out to $150 \mathrm{~km}$ when distance classes were pooled. Further, two-dimensional local alone, but were a common feature throughout the species' range. Such microgeographic genetic patchiness has been demonstrated in other marine species with planktonic larvae (e.g., Hedgecock 1994b, Knutsen et al. 2003, Pujolar et al. 2006), including several species along the Western Australian coast (Johnson \& Black 1982, Watts et al. 1990, Johnson et al. 1993, Johnson et al. 2001). Genetic patchiness has also been observed in P. cygnus using allozymes (Johnson \& Wernham 1999), but the scale of the genetic heterogeneity reported 
here is much smaller than shown previously. This likely reflects the increased genetic sensitivity and fine-scale geographic information of this study.

Spatial genetic patchiness in some species is due to temporal variation in the genetic composition of recruits (Johnson \& Black 1984, Watts et al. 1990, Hedgecock 1994a, Pujolar et al. 2006). This also seems to be the case for P. cygnus, in which a combination of temporal variation in allele frequencies and contrasting patterns of recruitment resulted in genetically different cohorts of P. cygnus at two sites (Johnson \& Wernham 1999). Furthermore, this pattern was ephemeral, as it was not repeated in the subsequent two years. Under the 'sweepstakes reproductive success' hypothesis (Hedgecock 1994a), temporal genetic variance in recruits might be a by-product of large variance in the reproductive success of individuals, owing to chance matching of reproductive activity with oceanographic conditions conducive for larval survival. Other possible explanations for temporal genetic variation in $P$. cygnus recruits are (1) origin from different source populations, (2) limited mixing of larvae in the plankton, or (3) natural selection on larvae prior to settlement. Given the low geographic structure in $P$. cygnus, it is unlikely that temporal genetic variation arises from different source populations. The finding that $P$. cygnus larvae settling at the same time at locations $350 \mathrm{~km}$ apart shared the same allele frequencies (Johnson \& Wernham 1999) also argues against temporal genetic variation being due to the cohesion of larvae in the plankton, though this result was based on only three allozyme loci.

If a combination of temporal variation in allele frequencies and contrasting patterns of recruitment is responsible for the genetic patchiness observed in this study, it would require juvenile $P$. cygnus to be relatively sedentary. This appears to be the case. Studies on foraging movements suggest juvenile $P$. cygnus forage over relatively small areas ( 150 m radius), though the extent of movement is variable (Jernakoff et al. 1987, Jernakoff \& Phillips 1988). The life-cycle of $P$. cygnus also includes a migratory phase, which occurs between four and 
294

295

296

297

298

299

300

301

302

303

304

305

306

307

308

309

310

311

312

313

314

315

316

317

318

six years of age, just after many lobsters undergo a synchronised moult that changes their normal red shell to a paler colour (Morgan et al. 1982). During this migration, lobsters leave the coastal reefs and move into deeper water breeding grounds, where they become sedentary again on deeper reefs. Because the lobsters we collected were predominantly from shallow water locations, it is unlikely that they had undertaken these migratory movements.

Nevertheless, tag and release experiments have shown that while large movements $(>200 \mathrm{~km})$ do occur, most lobsters $(>87 \%)$ are recaptured within $10 \mathrm{~km}$ of their release site (Chubb et al. 1999), which is within the distance range we detected positive population structure. More recently, a study using acoustic telemetry found that only a small proportion (13.6\%) of migratory phase lobsters emigrated from their resident reef, suggesting that a mass offshore migration may not hold for all inshore reefs (MacArthur et al. 2008).

Another explanation for spatial genetic patchiness is natural selection acting after settlement (Larson \& Julian 1999). Given the broad latitudinal range of P. cygnus (> 1200 $\mathrm{km})$, local populations are likely to experience highly varied environmental conditions, providing the opportunity for local adaptations to develop across populations (Kawecki \& Ebert 2004). Indeed, several studies have found evidence for local adaptation in widely distributed marine fish (see Nielsen et al. 2009). While we found no clear evidence of directional selection using outlier analysis, genome scans involving many more neutral markers, candidate genes or population transcriptomics would be needed to exclude confidently this possibility. A study monitoring the genetic composition of cohorts of recruits as they develop into adults would also yield valuable insights on post-settlement processes.

\section{Implications for fisheries management}

The implications of genetic patchiness for fisheries management have been discussed by Larson and Julian (1999). If genetic patchiness is due to selection after settlement, they 
suggest that the implications for fisheries management are minor, unless a fishery is concentrated on one particular habitat or location, which might disproportionately affect a certain portion of the gene pool. By contrast, factors affecting the genetic composition of recruits prior to settlement may have greater consequences. The most relevant of these to $P$. cygnus is the effect of stochastic spatial variation in the sources of successful larvae (sweepstakes reproductive success). This effect implies that the sources of successful larvae vary unpredictably over time. Fisheries management should therefore ensure that both the distribution as well as the total spawning potential of the exploited population is protected.

Further, spatial stochasticity of successful spawning argues for either the spatial dispersion of reserves (if they are involved in managing the exploitation), or suitably low exploitation rates across the fishery, thereby increasing the chance that at least some larvae will be released into conditions favourable for their survival. Local genetic patchiness also suggests juvenile and adult lobsters are comparatively sedentary, so they may be more susceptible to environmental/anthropogenic impacts at a finer scale than previously thought.

\section{Acknowledgements}

We thank Amanda Worth and Sherralee Lukehurst for technical assistance and the Western Australian Department of Fisheries for providing P. cygnus tissue samples. This project was funded by the Fisheries Research and Development Corporation (project 2009/020).

\section{References}

Antoa T, Lopes A, Lopes RJ, Beja-Pereira A, Luikart G (2008) LOSITAN: A workbench to

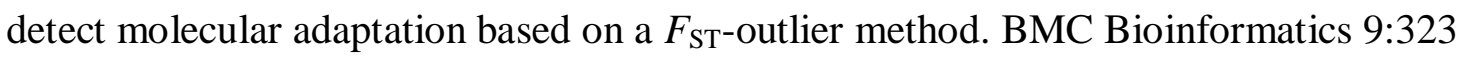
Ayre DJ, Hughes TP (2000) Genotypic diversity and gene flow in brooding and spawning corals along the Great Barrier Reef, Australia. Evolution 54:1590-1605 
Beaumont MA (2005) Adaptation and speciation: what can $F_{\text {ST }}$ tell us? Trends Ecol Evol $20: 435-440$

Beaumont MA, Nichols RA (1996) Evaluating loci for use in the genetic analysis of population structure. Proc R Soc Lond 363:1619-1626

Begg GA, Friedland KD, Pearce JB (1999) Stock identification and its role in stock assessment and fisheries management: an overview. Fish Res 43:1-8

Benzie JH, Stoddart JA (1992) Genetic structure of outbreaking and non-outbreaking crownof-thorns starfish (Acanthaster planci) populations on the Great Barrier Reef. Mar Biol 112:119-130

Bohonak AJ (1999) Dispersal, gene flow and population structure. Q Rev Biol 74:21-45

Carvalho GR, Hauser L (1994) Molecular genetics and the stock concept in fisheries. Rev Fish Biol Fisher 4:326-350

Chubb CF, Rossbach M, Melville-Smith R, Cheng YW (1999) Mortality, growth and movement of the western rock lobster (Panulirus cygnus). Final Report FRDC Project No. $95 / 020$

Diniz-Filho JAF, Telles MPC (2002) Spatial autocorrelation analysis and the identification of operational units for conservation in continuous populations. Conserv Biol 16:924-935

Double MC, Peakall R, Beck NR, Cockburn A (2005) Dispersal, philopatry, and infidelity: dissecting local genetic structure in superb fairy-wrens (Malurus cyaneus). Evolution $59: 625-635$

Evanno G, Regnaut S, Goudet J (2005) Detecting the number of clusters of individuals using the software STRUCTURE: a simulation study. Mol Ecol 14:2611-2620

Fletcher W, Chubb C, McCrea J, Caputi N, Webster F, Gould R, Bray T (2005) ESD Report Series No. 4 - Western Rock Lobster Fishery. Perth, WA 
García-Rodrguez FJ, Perez-Enriquez R (2008) Lack of genetic differentiation of blue spiny lobster Panulirus inflatus along the Pacific coast of Mexico inferred from mtDNA sequences. Mar Ecol Prog Ser 361:203-212

Gopal K, Tolley KA, Groeneveld JC, Matthee CA (2006) Mitochondrial DNA variation in spiny lobster Palinurus delagoae suggests genetically structured populations in the south-western Indian Ocean. Mar Ecol Prog Ser 319:191-198

Goudet J (2001) FSTAT, a program to estimate and test gene diversities and fixation indices (version 2.9.3).

Groth DM, Lim F, de Lestang SN, Beale N, Melville-Smith R (2009) Characterization of polymorphic microsatellite loci in the western rock lobster (Panulirus cygnus). Conserv Genet Resour 1:163-166

Guillot G, Mortier F, Estoup A (2005) GENELAND: a computer package for landscape genetics. Mol Ecol Notes 5:712-715

Hedgecock D (1986) Is gene flow from pelagic larval dispersal important in the adaptation and evolution of marine invertebrates? Bull Mar Sci 39:550-564

Hedgecock D (1994a) Does variance in reproductive success limit effective population sizes of marine organisms. In: Beaumont AR (ed) Genetics and evolution of aquatic organisms. Chapman and Hall, London

Hedgecock D (1994b) Spatial and temporal genetic structure of marine animal populations in the California current. CalCOFI Rep 35:73-81

Hedrick PW (2005) A standardized genetic differentiation measure. Evolution 59:1633-1638 Jernakoff P, Phillips BF (1988) Effect of a baited trap on the foraging movements of juvenile western rock lobsters, Panulirus cygnus George. Aust J Mar Fresh Res 39:185-192 
Jernakoff P, Phillips BF, Maller RA (1987) A quantitative study of nocturnal foraging distances of the western rock lobster Panulirus cygnus George. J Exp Mar Biol Ecol $113: 9-21$

Johnson MS, Bentley SL, Ford SS, Ladyman MT, Lambert GJ (2001) Effects of a complex archipelago on genetic subdivision of the intertidal limpet Siphonaria kurracheensis. Mar Biol 139:1087-1094

Johnson MS, Black R (1982) Chaotic genetic patchiness in an intertidal limpet, Siphonaria sp. Mar Biol 70:157-164

Johnson MS, Black R (1984) Pattern beneath the chaos: the effect of recruitment on genetic patchiness in an intertidal limpet. Evolution 38:1371-1383

Johnson MS, Black R (2006a) Effects of mode of reproduction on genetic divergence over large spatial and temporal scales in intertidal snails of the genus Bembicium Philippi (Gastropoda: Littorinidae). Biol J Linn Soc 89:689-704

Johnson MS, Black R (2006b) Islands increase genetic subdivision and disrupt patterns of connectivity of intertidal snails in a complex archipelago. Evolution 60:2498-2506

Johnson MS, Holborn K, Black R (1993) Fine-scale patchiness and genetic heterogeneity of recruits of the corallivorous gastropod Drupella cornus. Mar Biol 117:91-96

Johnson MS, Wernham J (1999) Temporal variation of recruits as a basis of ephemeral genetic heterogeneity in the western rock lobster Panulirus cygnus. Mar Biol 135:133139

Jørgensen HBH, Hansen MM, Bekkevold D, Ruzzante DE, Loeschcke V (2005) Marine landscapes and population genetic structure of herring (Clupea harengus L.) in the Baltic Sea. Mol Ecol 14:3219-3234

Kawecki TJ, Ebert D (2004) Conceptual issues in local adaptation. Ecol Lett 7:1225-1241 
415 Kennington WJ, Cadee SA, Berry O, Groth DM, Johnson MS, Melville-Smith R (2013)

416 Maintenance of genetic variation and panmixia in the commercially exploited western rock lobster (Panulirus cygnus). Conserv Genet 14:115-124

Kennington WJ, Levy E, Berry O, Groth DM, Waite AM, Johnson MS, Melville-Smith R

Knutsen H, Jorde PE, André C, Stenseth NC (2003) Fine-scaled geographical population structuring in a highly mobile marine species: the Atlantic cod. Mol Ecol 12:385-394

Larson RJ, Julian RM (1999) Spatial and temporal genetic patchiness in marine populations and their implications for fisheries management. CalCOFI Rep 40:94-99

Lee HJE, Boulding EG (2009) Spatial and temporal population genetic structure of four northeastern Pacific littorinid gastropods: the effect of mode of larval development on variation at one mitochondrial and two nuclear DNA markers. Mol Ecol 18:2165-2184

MacArthur LD, Babcock RC, Hyndes GA (2008) Movements of the western rock lobster (Panulirus cygnus) within shallow coastal waters using acoustic telemetry. Mar Freshwater Res 59:603-613

Meirmans PG, Hedrick PW (2011) Assessing population structure: $F_{\mathrm{ST}}$ and related measures. Mol Ecol Resour 11:5-18

Morgan GR, Phillips BF, Joll LM (1982) Stock recruitment relationships in Panulirus cygnus the commercial rock (spiny) lobster of Western Australia. Fish Bull 80:475-486

Naro-Maciel E, Reid B, Holmes K, Brumbaugh D, Martin M, DeSalle R (2011) Mitochondrial DNA sequence variation in spiny lobsters: population expansion, panmixia, and divergence. Mar Biol 158:2027-2041

Nielsen EE, Hemmer-Hansen J, Larsen PF, Bekkevold D (2009) Population genomics of marine fishes: identifying adaptive variation in space and time. Mol Ecol 18:3128-3150 
440 Ovenden JR, Brasher DJ, White RWG (1992) Mitochondrial DNA analyses of the red rock $441 \quad$ lobster Jasus edwardsii supports an apparent absence of population subdivision throughout Australasia. Mar Biol 112:319-326

Palero F, Abellób P, Macpherson E, Gristinad M, Pascual M (2008) Phylogeography of the European spiny lobster (Palinurus elephas): Influence of current oceanographical features and historical processes Mol Phylo Evol 48:708-717

Palumbi SR (1994) Genetic divergence, reproductive isolation, and marine speciation. Annu Rev Ecol Syst 25:547-572

Peakall R, Ruibal M, Lindenmayer DB (2003) Spatial autocorrelation analysis offers new insights into gene flow in the Australian bush rat, Rattus fuscipes. Evolution 57:11821195

Peakall R, Smouse PE (2005) GenAlEx V6: Genetic analysis in Excel. Population genetic software for teaching and research. Australian National University, Canberra. Available via http://www.anu.edu.au/BoZo/GenAlEx

Perez-Enriquez R, Vega A, Avila S, Sandoval JL (2001) Population genetics of red spiny lobster (Panulirus interruptus) along the Baja California Peninsula, Mexico. Mar Freshwater Res 52:1541-1549

Phillips BF, Brown PA, Rimmev DW, Reid DD (1979) Distribution and dispersal of the phyllosoma larvae of the western rock lobster, Panulivus cygnus, in the south-eastern Indian Ocean. Aust J Mar Fresh Res 30:773-783

Pritchard JK, Stephens M, Donnelly P (2000) Inference of population structure using multilocus genotype data. Genetics 155:945-959

Pritchard JK, Wen X, Falush D (2010) Documentation for structure software: version 2.3. http://pritchbsduchicagoedu/structurehtml 
Pujolar JM, Maes GE, Volckaert FAM (2006) Genetic patchiness among recruits in the European eel Anguilla anguilla. Mar Ecol Prog Ser 307:209-217

Riccioni G, Landi M, Ferrara G, Milano I, Cariani A, Zane L, Sella M, Barbujani G, Tinti F (2010) Spatio-temporal population structuring and genetic diversity retention in depleted Atlantic Bluefin tuna of the Mediterranean Sea. Proc Natl Acad Sci USA 107:2102-2107 Rice WR (1989) Analyzing tables of statistical tests. Evolution 43:223-225

Ruzzante DE, Taggart CT, Cook D, Goddard S (1996) Genetic differentiation between inshore and offshore Atlantic cod (Gadus morhua) off Newfoundland: microsatellite DNA variation and antifreeze level. Can J Fish Aquat Sci 53:634-645

Silberman JD, Sarver SK, Walsh PJ (1994) Mitochondrial DNA variation and population structure in the spiny lobster Panulirus argus. Mar Biol 120:601-608

Slatkin M (1995) A measure of population subdivision based on microsatellite allele frequencies. Genetics 139:457-462

Smouse PE, Peakall R (1999) Spatial autocorrelation analysis of individual multiallele and multilocus genetic structure. Heredity 82:561-573

Thompson AP, Hanley JR, Johnson MS (1996) Genetic structure of the western rock lobster, Panulirus cygnus, with the benefit of hindsight. Mar Freshwater Res:889-896

Tolley KA, Groeneveld JC, Gopal K, Matthee CA (2005) Mitochondrial DNA panmixia in spiny lobster Palinurus gilchristi suggests a population expansion. Mar Ecol Prog Ser 297:225-231

van Oosterhout C, Hutchinson WF, Wills DPM, Shipley P (2004) MICROCHECKER: software for identifying and correcting genotyping errors in microsatellite data. Mol Ecol Notes 4:535-538

Waples RS (1987) A multispecies approach to the analysis of gene flow in marine shore fishes. Evolution 41:385-400 
489 Watts RJ, Johnson MS, Black R (1990) Effects of recruitment on genetic patchiness in the 490 urchin Echinometra mathaei in Western Australia. Mar Biol 105:145-151

491 Weir BS, Cockerham CC (1984) Estimating $F$-statistics for the analysis of population $492 \quad$ structure. Evolution 38:1358-1370

493 White TA, Stamford J, Hoelzel AR (2010) Local selection and population structure in a deep494 sea fish, the roundnose grenadier (Coryphaenoides rupestris). Mol Ecol 19:216-226 495

496 
Table 1. Genetic variation at each location.

\begin{tabular}{lllll}
\hline Site & Sample size & $\mathrm{A}_{\mathrm{R}}(\mathrm{SE})$ & $H(\mathrm{SE})$ & $F_{\mathrm{IS}}$ \\
\hline Kalbarri & $39.4(0.3)$ & $7.1(1.9)$ & $0.58(0.11)$ & $-0.05^{\mathrm{NS}}$ \\
HA1 & $38.9(0.4)$ & $7.8(2.0)$ & $0.62(0.10)$ & $0.01^{\mathrm{NS}}$ \\
Dongara & $38.2(0.7)$ & $7.2(1.8)$ & $0.62(0.10)$ & $-0.01^{\mathrm{NS}}$ \\
Jurien Bay & $38.3(0.6)$ & $7.3(2.0)$ & $0.60(0.10)$ & $-0.01^{\mathrm{NS}}$ \\
North Lancelin & $17.7(0.6)$ & $7.2(2.0)$ & $0.56(0.11)$ & $-0.04^{\mathrm{NS}}$ \\
Lancelin & $35.9(0.7)$ & $7.0(1.8)$ & $0.59(0.11)$ & $0.03^{\mathrm{NS}}$ \\
Rottnest Island & $63.0(0.2)$ & $7.5(1.9)$ & $0.64(0.11)$ & $-0.03^{\mathrm{NS}}$ \\
Fremantle & $20.4(0.2)$ & $6.8(1.8)$ & $0.61(0.10)$ & $-0.01^{\mathrm{NS}}$ \\
Mandurah & $21.4(0.2)$ & $7.3(1.8)$ & $0.61(0.10)$ & $0.00^{\mathrm{NS}}$ \\
\hline
\end{tabular}

$\mathrm{A}_{\mathrm{R}}$ : allelic richness (based on a sample size of 14 individuals); $H$ : gene diversity. ${ }^{\mathrm{NS}}$

499 designates no significant deviation from Hardy-Weinberg equilibrium. 
Table 2. Pairwise $G$ "' ${ }_{\text {ST }}$ estimates (below diagonal) and $P$-values from tests of differentiation (above diagonal) between geographic locations.

502 The adjusted significance level for multiple comparisons is 0.0014. Significant divergences are highlighted in bold text.

\begin{tabular}{|c|c|c|c|c|c|c|c|c|c|}
\hline & Kalbarri & HA1 & Dongara & Jurien Bay & N. Lancelin & Lancelin & Rottnest Is. & Fremantle & Mandurah \\
\hline Dongara & 0.023 & 0.010 & - & 0.333 & 0.006 & 0.157 & 0.591 & 0.201 & 0.650 \\
\hline North Lancelin & 0.017 & 0.007 & 0.037 & 0.002 & - & 0.431 & 0.025 & 0.352 & 0.251 \\
\hline Lancelin & 0.009 & 0.006 & 0.008 & -0.004 & 0.001 & - & 0.433 & 0.110 & 0.603 \\
\hline Rottnest Island & -0.005 & 0.026 & -0.002 & -0.003 & 0.023 & 0.001 & - & 0.278 & 0.789 \\
\hline
\end{tabular}

503 
509 Fig. 1 Locations where P. cygnus samples were collected.

510

511 Fig. 2 Spatial autocorrelation analyses. (A) Correlogram plot of the genetic correlation coefficient ( $r$ ) as a function of distance. (B) Multiple distance class plot, showing the influence of different distance class sizes on genetic correlation. Permuted $95 \%$ confidence

514 interval (dashed lines) and the bootstrap 95\% confidence error bars are shown.

515

516 Fig. 3 Plot of two-dimensional local spatial autocorrelation analyses. Symbols represent geographical coordinates with significantly positive (red circles) or non-significant (crosses)

518 $l r$ values. Calculations of $l r$ were based on sampling the nearest 20 individuals. For clarity significantly positive values were offset by $-0.1^{\circ}$ longitude.

520

521 


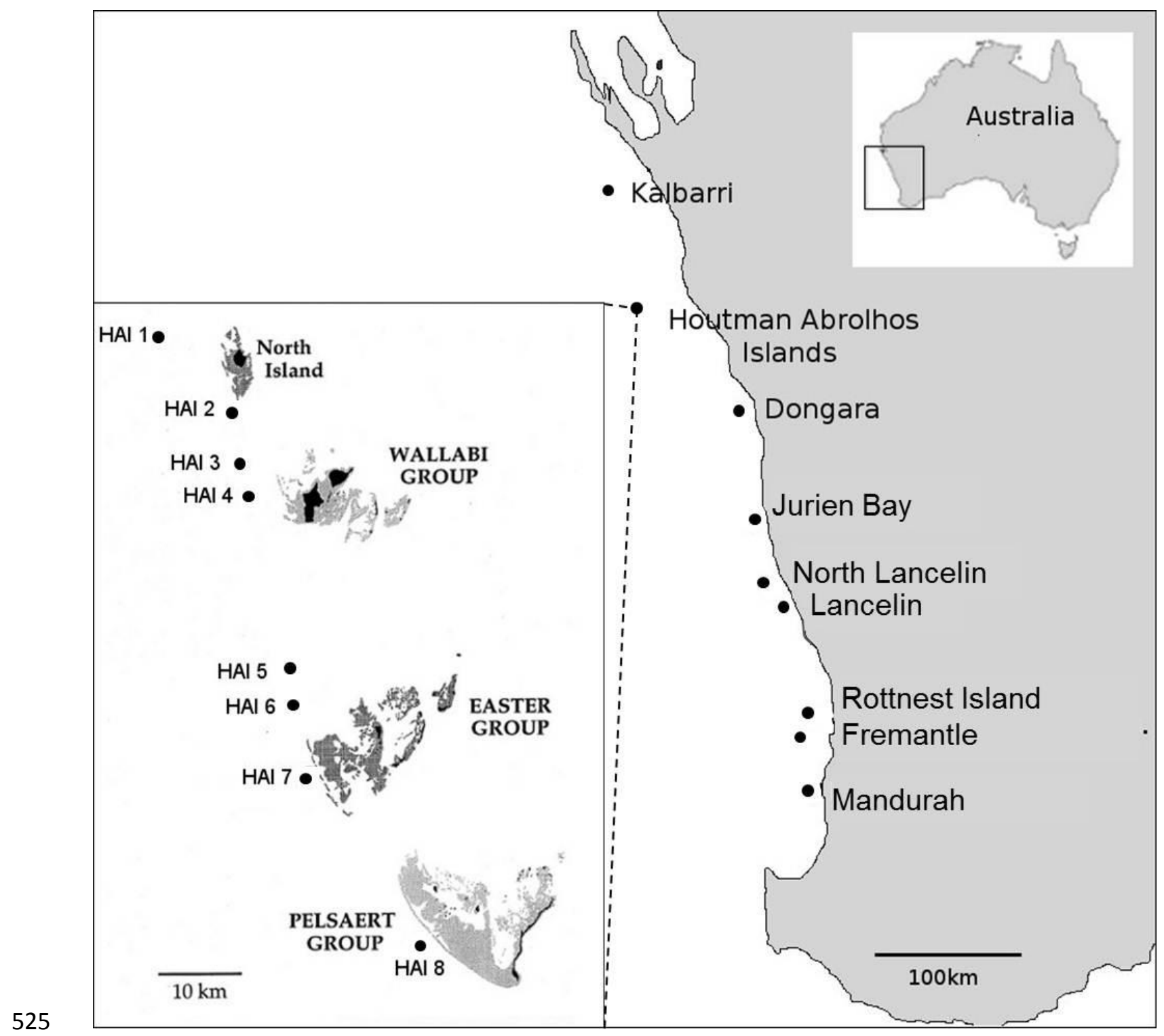

526 
A

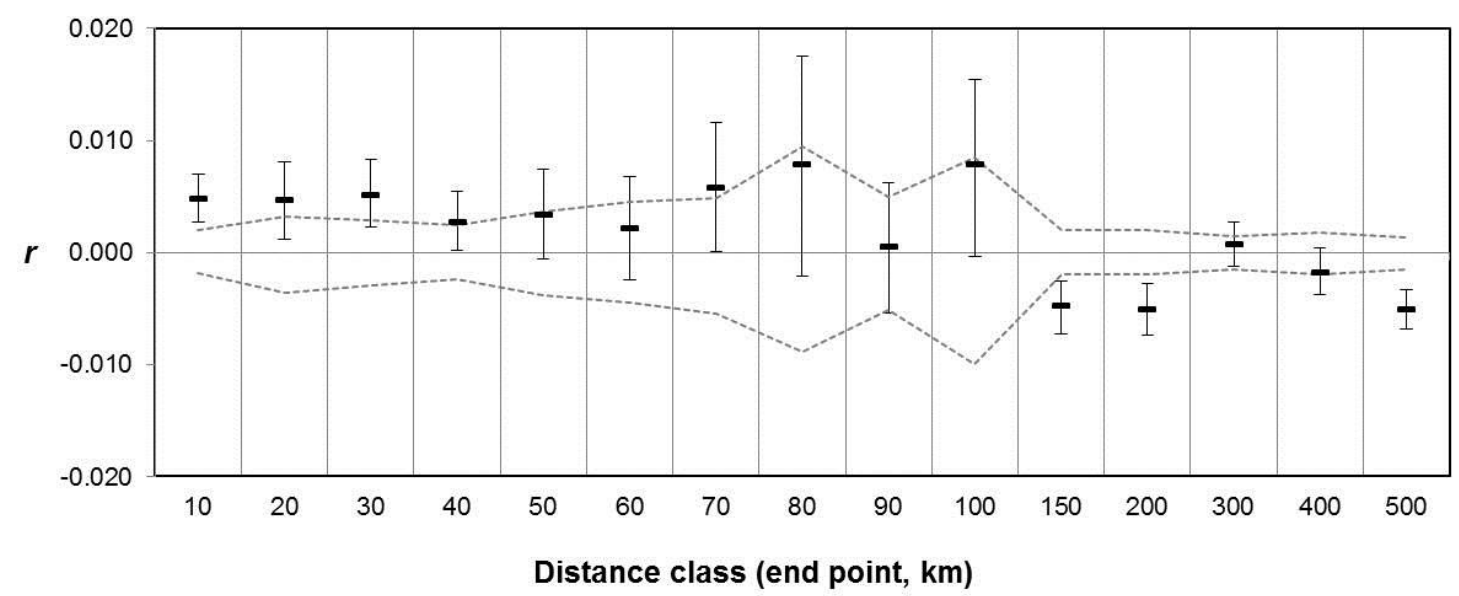

B

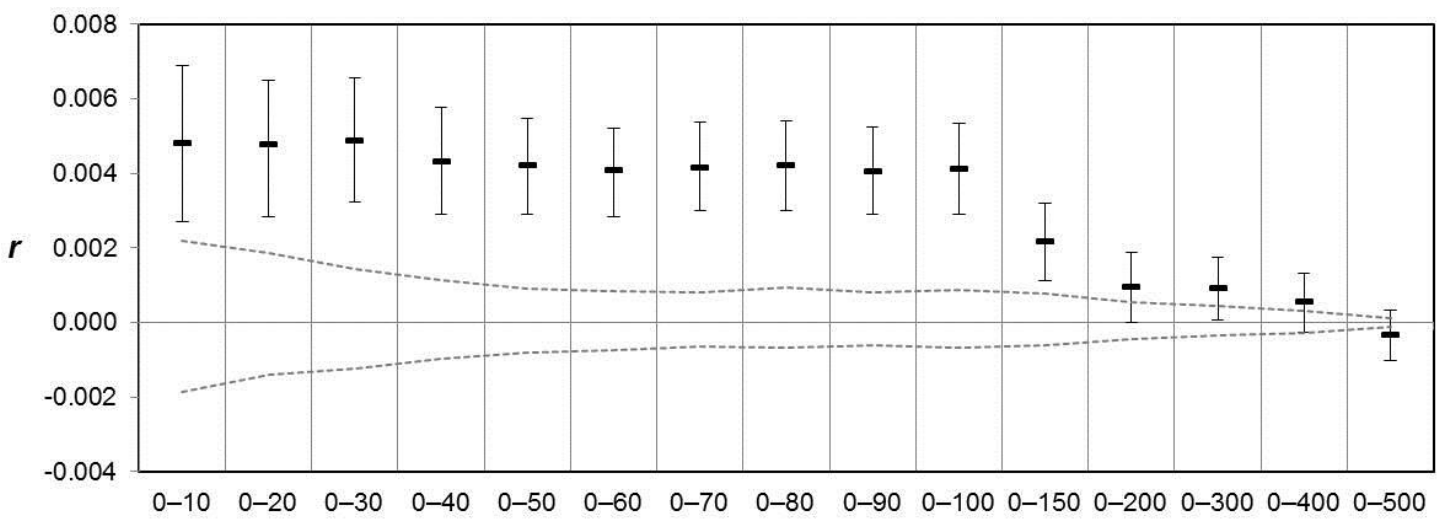

531

Distance class (km)

532

533 

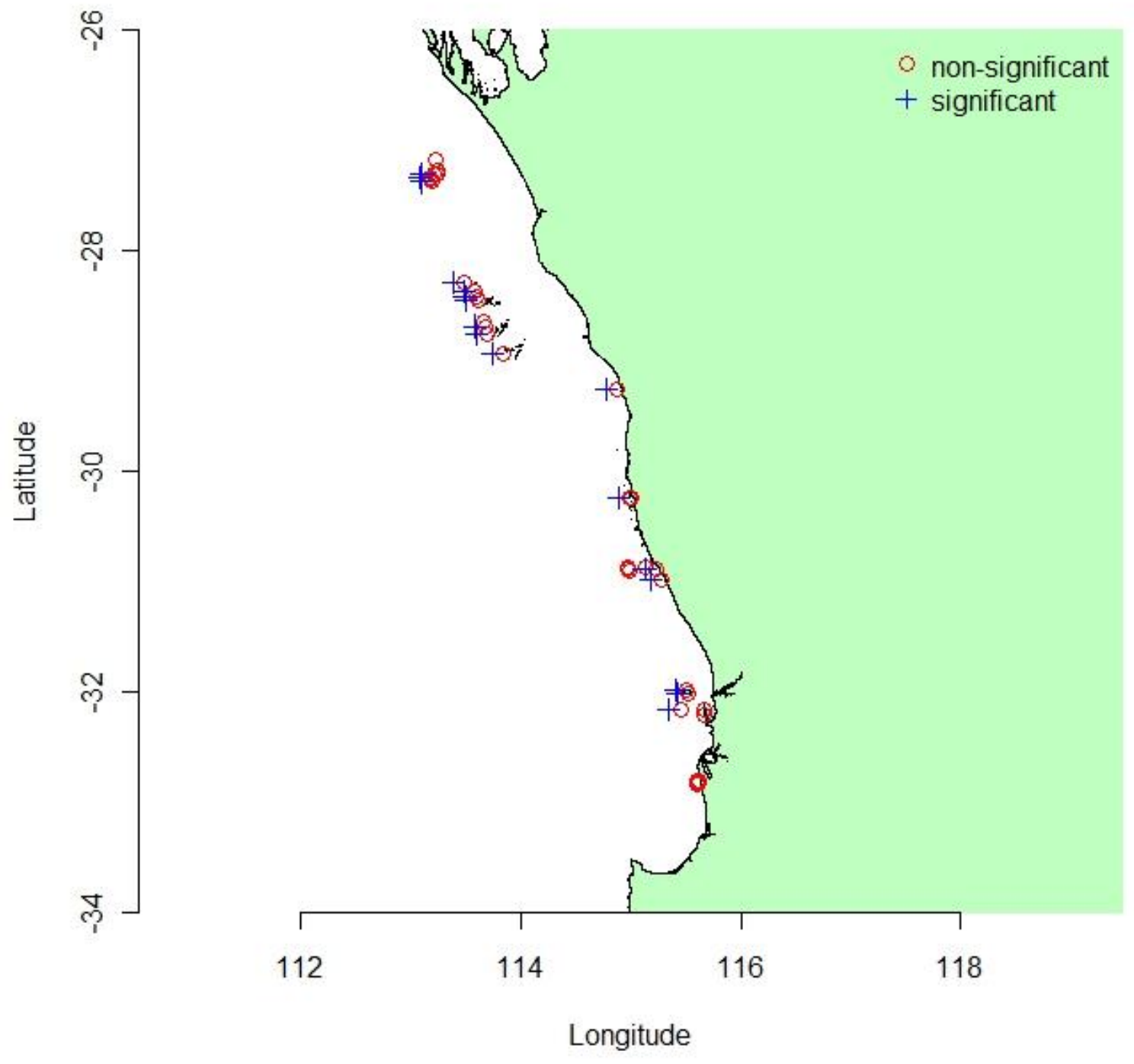